\title{
Environmental Impacts of Corrosion on the Physical Properties of Copper and Aluminium: A Case Study of the Surrounding Water Bodies in Port Harcourt
}

\author{
Elenwo Ephraim Ikechukwu1 ${ }^{*}$, Elenwo Onyinyechi Pauline ${ }^{2}$ \\ ${ }^{1}$ Department of Geography and Environmental Management, University of Port Harcourt, \\ Choba, Nigeria \\ ${ }^{2}$ Department of Physics, University of Port Harcourt, Choba, Nigeria \\ Email: ${ }^{*}$ lyke2 elenwo@yahoo.com, ephraimelennwo@gmail.com
}

Received 22 January 2015; accepted 12 February 2015; published 16 February 2015

Copyright (C) 2015 by authors and Scientific Research Publishing Inc.

This work is licensed under the Creative Commons Attribution International License (CC BY). http://creativecommons.org/licenses/by/4.0/

c) (i) Open Access

\begin{abstract}
Environmental impacts are the changes that are observed on structures, metals, and other objects directly and indirectly on the environment. This research investigated the effects of corrosion on the physical properties of copper and aluminium materials. Water samples were collected from water bodies around Port Harcourt environs, including rain water. The materials used for the research (copper and aluminium) were pre-weighed and weight noted. Using the weight-loss technique, the following observations was made on, the density, the sample exposed area and the times of exposure were all affected by the water samples. The results showed that marginal reduction in densities and the average corrosion rate for the metals was estimated in mills per year (MPY) as follows; for Aluminium $3.0770 \mathrm{~g} / \mathrm{cm}^{3}$ from day (1) week (1) $1.3753 \mathrm{~g} / \mathrm{cm}^{3}$ on day (31) week 4 after exposure in fresh water, and in brackish water, 0.5999 on 31st week (4) and no change for the (4) weeks in rain water. while for copper exposure to fresh water showed 0.6675 $\mathrm{g} / \mathrm{cm}^{3}$ on day 31 week (4), brackish water, day (1) $1.375 \mathrm{~g} / \mathrm{cm}^{3}$ and 0.179 on day 31st week (4) and on Rain water on day $31 \mathrm{st}$ week (4) $0.241 \mathrm{~g} / \mathrm{cm}^{3}$ respectively.
\end{abstract}

\section{Keywords}

Environmental, Impact, Corrosion, Physical Properties, Copper, Aluminum

\footnotetext{
${ }^{*}$ Corresponding author.
} 


\section{Introduction}

The environment as defined in [1] as the components of the earth and includes:

a) Land, Water, and Air including all layers of the atmosphere;

b) All organic and inorganic matter and living organisms;

c) The interacting natural systems that include components referred to (a) and (b) above.

Environmental impacts are observed in several objects within the Niger Delta Region of Nigeria and beyond. Environmental impacts are the changes that are observed on structures, metals, and other objects directly and indirectly on the environment. These impacts are influenced by changes in atmospheric conditions exaggerated by natural and anthropogenic factors [2]. Every metal has the natural tendency to revert back to its original mineral form, and the more lightly processed finished metal, the more easily the reversion phenomena occurs [3].

Corrosion of steel or metal is an electro-chemical reaction between the metal and its environment in which the metal revert to iron oxide. The electro-chemical process causes a gradual alteration or wearing away of the metal surface and since the process returns the metal to its stable thermodynamic state, the action is considered as a degradation of the material [4]. For corrosion to take place there must be the presence of an electrolyte like water, salt water, soil or charged liquid medium. The chemical process induces electricity to flow from a negatively charged area to a more positively charged area in an electro potential difference leading to corrosion. However, the appearance of rusted metal work is not very much acceptable in usual industrial practice.

More so, due to metals numerous application in industrial and technological sector of development, an indepth study of corrosion, its form, prevention and control measures, its impact and physical properties of metals is necessary. Therefore, a study of the corrosion on physical properties of Copper and Aluminum materials is investigated by this research.

\subsection{An over View of Corrosion}

Over the years, it has been observed that the use of metals in our industries and technological development has failed due to corrosion. Several techniques for corrosion control and protection have been developed. Sol-Gel coating and cathodic electrode methods [5] are some of the methods that are available as means of reducing the effects of environment upon the damage caused on metallic materials.

Though most metals for example, Copper and Aluminum are known for producing thin films to cover its surface when attracted by a corrosive environment. According to [6], some accidents in industries, plane crash, pipe line explosion, collapse of bridges are all associated to corrosion effect. Corrosion of oil pipelines buried in the soil has become the most serious concern to the oil industry operators. Soil corrosion is as a result of differential concentration cells involving oxygen, water and various chemical in the soil [2]. Various contributing factors to corrosion of oil pipeline have been identified to include; incomplete removal of mill scale on piping, bacterial action, pinholes in protective coatings and coupling of dissimilar metals. According to [4], four major categories of corrosion were identified and thus;

Group I: Corrosions are those usually distinguished by naked eyes. They are identified primarily as to the distribution of attack. Corrosion in this group occurs over the whole or most of the exposed surface of the material like rusting of steel in the atmosphere, localized corrosion covers only a fraction of the total surface area. Bimetallic or galvanic corrosion in this category occurs when a metal is electrically coupled to another metal or a nonmetal in electrolyte. The more anode member corrodes more rapidly than the more cathodic member. The cathodic member is protected by the galvanic corrosion of the anode. Group II: Corrosion includes velocity rated corrosion, intergranular and dealloying corrosion. While velocity related corrosion arises from conditions set up by flow of a corrosives environment. Cavitations corrosion occurs when condition of fluid set up by low pressure areas between metal and environment such that the liquid vapourizes and forms bubbles. The bubbles alternately form and collapse in the liquid impacting and distributing either otherwise protective films or even the metal itself.

Inter granular and dealloying corrosion belongs to this group and are both related to corrosion of alloys along individual grain boundaries and preferential dissolution of one component of an alloy respectively. Group III: Corrosion are just like those in group II described and are defined in terms of morphology, the shape, size, or direction of corrosion. Commonest occurrences here are cracking and high temperature corrosion.

Group IV: Bacteria and other micro organisms can induce corrosion on metals in a variety of ways [4]. Corrosion effect in this group can be either by direct or indirect means. Direct effect, where micro organisms con- 
sumes metals as a part of their respiratory process. The indirect effect results through the excretion of by-products as part of their natural respiratory process. Common by-products of their respiratory process include carbon dioxide, hydrogen sulphide, ammonia, organic and in organicacids. Therefore, to maintain the integrity of oil pipeline installation, engineering practice is to continually carryout inspection, examination and testing of the pipelines.

\subsection{Corrosion and Properties of Materials}

Corrosion is the disintegration of an engineered material into its constituent atoms due to chemical reactions with its surroundings, this further means that corrosion is an electrochemical oxidation of metals in reaction with an oxidant such as oxygen [7]. The formation of an oxide of iron due to oxidation of the iron atom in solid solution is electrochemical corrosion, commonly known as rusting. Simply put, corrosion is the wearing away of metals due to a chemical reaction. There is no clear and exact number of corrosion forms. According to [7]; the most common and destructive forms of corrosion exist as follows:

Galvanic corrosion: This form of corrosion occurs when two different metals electrically contact each other and are immersed in an electrolyte. In order for galvanic corrosion to occur, an electrically conductive path and an ionic ally conductive are necessary. Galvanic corrosion is often utilized in sacrificial anodes. The conductive pathway or solution may be sea water or road salt sprays which contain chloride or rain, moist or dew containing sulphur or nitrogen compounds.

Crevice Corrosion: This is a localized corrosion form occurring in spaces to which the access of the working fluid from the environment is limited and a concentration cell, area with different oxygen concentration will take place with consequent high corrosion rate. Pitting: This is another form of corrosion which is extremely localized. Its attack on metals results in holes on metals. It is one of the most destructive and insidious forms of corrosion. It causes equipment failure due to perforation with only a small percent weight loss of the entire structure. It starts gradually and spreads rapidly and is accelerated by the presence of chloride and is common at base of break of coatings.

Stress-corrosion cracking: This is cracking caused by the simultaneous presence of tensile stress and a specific corrosive medium. During stress-corrosion cracking, the alloy is virtually unattached over most of its surface, while fine cracks progress through it. Selective leaching: This is the removal of one element from a solid alloy by corrosion process. The most common example is the selective removal of Zinc in brass alloys (dezincification). Intergranular corrosion: If a metal corrodes, uniform attack results since grain boundaries are usually only slightly more reactive than the matrix. However, under certain conditions, grain interfaces are very reactive and intergranular corrosion results. Hydrogen damage: This is a general term which refers to the mechanical damage of a metal caused by the presence of or interaction with hydrogen.

Atmospheric corrosion: This type of corrosion and its severity is essentially determined by four variables; air, pollution, air borne salt, salt sprays and droplets, temperature and moisture. The presence of air pollution such as nitrogen and sulphur compounds may form acids when discharged or acidic material may be released to the atmosphere directly by some industries, accelerating the corrosion process on metals these substances encounter. Atmospheric corrosion is ubiquitous and is responsible for more metal damage than any other form of environmental corrosion.

\subsection{Sources of Corrosion}

There are several sources which could enhance the process of corrosion. According to [7] these sources could be grouped into environment, compound design, fabrication method, welds and replacement of failed materials.

Environment: This could be regarded as the greatest sources of corrosion, since all materials must exist in one environment or the other. The environmental constituents such as the presence of salt sprays, acids bases and corrosives are potential sources of corrosion. Compound Design: In the industry, materials are designed to fit into another. IF there is a mismatch of metallic component, one of the components may acts as an anode and the other cathode, giving rise to galvanic corrosion in a suitable environment.

Fabrication method: In the industry, fabrication of material will eventually cause the failure of the material if there is a considerable amount of load applied to it. Also, improper treatment of material may bring a reasonable grain boundary problem thereby making the material vulnerable to rapid corrosion. Welds: Excessive weld bumps on a material will cause a change in velocity of fluids flowing through the material (pipe) due to in- 
creased flow resistance. This will cause corrosion of the metal from the weld point. Replacement of failed material: This situation is very common. A replaced materials compatibility with other parts is very important because an unfit material (different from the existing ones) may facilitate galvanic corrosion. Improper replacement procedures and finishing may bring an increase in corrosion rate.

\subsection{Prevention and Control of Corrosion}

The fact that the use of metals cannot be eliminated in our daily development presupposes that the prevention and control of corrosion is in evitable. There are some methods of prevention and control as follows: Material selection: The most common method of preventing corrosion is the selection of the proper material or alloy for a particular corrosive service for example, stainless steel has an excellent resistance in a nitric acid service. Also, for a reducing or non oxidizing environment such as air, free acid and aqueous solution, nickel, copper and their alloy can be used while for an oxidizing condition, chromium containing alloys are effective.

\section{Alteration/Modification of Environment}

Altering the environment provides a versatile means for reducing corrosion. These can be done in several ways:

a) Lowering temperature causes a pronounce decrease in corrosion rate.

b) Very high velocities should be avoided because velocities generally increase corrosive attack.

c) Removal of oxygen or oxidizers in most environments decreases corrosion rate, but it is not favourable for active-passive metal or alloys since they require oxidizers to form and maintain protective films.

d) Changing the concentration of a corrosive solution will reduce the rate of corrosion.

e) Inhibitors can be used to stop or reduce corrosion. They can be considered as retarding catalyst. Cathodic protection: The protection is achieved by supplying electrons to the metal structure to be protected. There are two ways to catholically protect a structure by an external power supply or by appropriate galvanic coupling.

Coating: Coatings can be used to provide a satisfactory barrier between a metal and its environment. Metallic or inorganic materials can be used for these. Metal coatings are applied by electro deposition or electroplating, flame spray or metalizing, hot dipping and vapour deposition while inorganics are applied by spraying diffusion or chemical conversion. Design: Designers should consider mechanical and strength requirement together with an allowance for corrosion. Mechanical design of a component should be based on the material of construction. This is an important factor to recognize, since materials of construction used for corrosion resistance vary widely in their mechanical characteristics.

\section{Physical Properties of Copper and Aluminum}

\subsection{Copper (Physical Properties)}

Copper occupies the same family of the periodic table as silver and gold. Since they each have one s-orbital electron on top of a filled electron shell which form metallic bonds. Copper is easily worked, being both ductile and malleable. The ease with which it can be drawn into wire makes it useful for electrical work as does its excellent electrical conductivity. Copper has reddish or brownish colour owing to a thin layer of tarnish (including oxides). Pure copper is pink or peached coloured and is generally produced from a multi stage process, beginning with the mining and concentration of low grade ores containing copper sulphide minerals and followed by smelting and electrolytic refining to produce a pure copper cathode.

\subsection{Aluminum (Physical Properties)}

Aluminum is a soft, durable, light weight, ductile and malleable metal with appearance ranging from silvery to dull gray, depending on the surface roughness. Aluminum is nonmagnetic and non sparkling. It is also non insoluble in alcohols though it can be soluble in water in forms. Aluminum has about one third the density and stiffness of steel. It is easily machined, cast, drawn and extruded. Aluminum is a good thermal and electrical conductor, having $62 \%$ the conductivity of copper. Density is of great importance for aluminum, very many applications exploit its combination of good mechanical, thermal or electrical performance at low weight (e.g. in transportation). Aluminum is cheaper and lighter than competing metals (such as copper, gold and silver). 


\section{Method of the Study}

\section{Acquisition and Preparation of Samples}

Copper and Aluminum metals were purchased from the open market. They were cut into $2 \mathrm{~cm}$ by $4 \mathrm{~cm}$ of 20 pieces each. They were sand papered to expose shining surfaces and to remove any existing corrosion effect. Water samples from the surrounding rivers in Port Harcourt (the brackish water swamp and the fresh water swamp) were collected with 1.5 liter plastic bottle. Also, some quantity of rain water was collected in a basin and put in a plastic bottle. The metal samples were pre-weighed before dipping them into each of the container provided for the water samples for four weeks. A piece of each of sample metal was kept as "Reserved" AR for reference or as control. Samples of each of the metal were brought out after the first week on first (1st), third (3rd), fifth (5th) and seventh (7th) days for four weeks. The retrieved metal samples were weighed to determine the new mass for four weeks, one month respectively. Prior to this period the initial weight of the metal were noted. Thus, by applying the weight-loss techniques and the equation by [7].

MPY (mills per year) $=534 \mathrm{~W}$.

DAT

where $=$ weight loss (mg).

$\mathrm{D}=$ Density of sample $\left(\mathrm{g} / \mathrm{cm}^{3}\right)$.

$\mathrm{A}=$ Area of specimen exposed to corrosion $\left(\mathrm{cm}^{2}\right)$.

$\mathrm{T}=$ Period of exposure (hrs).

The corrosion rate for each of the metal samples was estimated as observed from the experiment. The results are shown in the Table 1 and Table 2.

\section{Results}

\subsection{Discussion}

The measured average densities of Aluminium and Copper in the various water samples are reported as follows; in Table 1 and Table 2 as well as rate of corrosion measured in mills per year (MPY). The density reductions and corrosion were noticed as follows; for Aluminum $3.0770 \mathrm{~g} / \mathrm{cm}^{3}$ from day (1) week (1) $1.3753 \mathrm{~g} / \mathrm{cm}^{3}$ on day (31) week 4 after exposure in fresh water, and in brackish water, 0.5999 on 31st week (4) and no change for the (4) weeks in rain water. while for copper exposure to fresh water showed $0.6675 \mathrm{~g} / \mathrm{cm}^{3}$ on day 31 week (4), brackish water, day (1) $1.375 \mathrm{~g} / \mathrm{cm}^{3}$ and 0.179 on day 31st week (4) and on Rain water on day 31st week (4)

Table 1. Corrosion rate of Aluminum in fresh, brackish and rainwater.

\begin{tabular}{cccc}
\hline Days & $\begin{array}{c}\text { Corrosion rates (MPY) of } \\
\text { Al in freshwater }\end{array}$ & $\begin{array}{c}\text { Corrosion rates (MPY) of } \\
\text { Al in brackish water }\end{array}$ & $\begin{array}{c}\text { Corrosion rates (MPY) of } \\
\text { Al in rainwater }\end{array}$ \\
\hline 1 & 3.0770 & - & - \\
3 & 1.9730 & 1.8704 & - \\
5 & 1.8690 & 1.7919 & - \\
7 & 1.6979 & 1.7624 & - \\
9 & 1.7137 & 1.6918 & - \\
11 & 1.7033 & 1.5309 & - \\
13 & 1.6800 & 1.3781 & - \\
15 & 1.5830 & 1.2032 & - \\
17 & 1.6286 & 1.0615 & - \\
19 & 1.6231 & 0.9738 & - \\
21 & 1.5735 & 0.8809 & - \\
25 & 1.6291 & 0.7838 & - \\
27 & 1.4691 & 0.731 & - \\
\hline
\end{tabular}


$0.241 \mathrm{~g} / \mathrm{cm}^{3}$ respectively. Thus, it was generally observed that there was a gradual decrease in weight with time in each of the samples in a given environment. This gradual decrease in weight will give rise to increasing weight losses over a year period. This was basically observed in this research, because increased acidity or alkalinity is one of the conditions for increasing corrosion depending on other prevailing conditions in each environment. This also exacerbated the rate of corrosion as reported. The measurement were also plotted as reported in Figure 1 and Figure 2 for rate of corrosion and Figure 3 and Figure 4 for comparison of the two metals in

Table 2. Corrosion rate of copper in fresh, brackish and rainwater.

\begin{tabular}{cccc}
\hline Days & $\begin{array}{c}\text { Corrosion rates (MPY) of } \\
\text { Cu in freshwater }\end{array}$ & $\begin{array}{c}\text { Corrosion rates (MPY) of } \\
\text { Cu in brackish water }\end{array}$ & $\begin{array}{c}\text { Corrosion rates (MPY) of } \\
\text { Cu in rainwater }\end{array}$ \\
\hline 1 & - & 1.375 & - \\
3 & 2.213 & 0.7229 & 0.1492 \\
5 & 1.3056 & 0.5329 & 0.0936 \\
7 & 0.933 & 0.5103 & 0.0843 \\
9 & 0.7655 & 0.4582 & 0.0689 \\
11 & 0.6033 & 0.4614 & 0.0574 \\
13 & 0.5294 & 0.3584 & 0.0439 \\
15 & 0.4344 & 0.3239 & 0.0437 \\
17 & 0.8103 & 0.3123 & 0.0387 \\
21 & 0.6996 & 0.2782 & 0.0355 \\
23 & 0.6328 & 0.2508 & 0.0324 \\
25 & 0.8543 & 0.2354 & 0.0298 \\
27 & 0.7859 & 0.2204 & 0.0275 \\
\hline 1 & 0.7654 & 0.2035 & 0.0254 \\
\hline
\end{tabular}

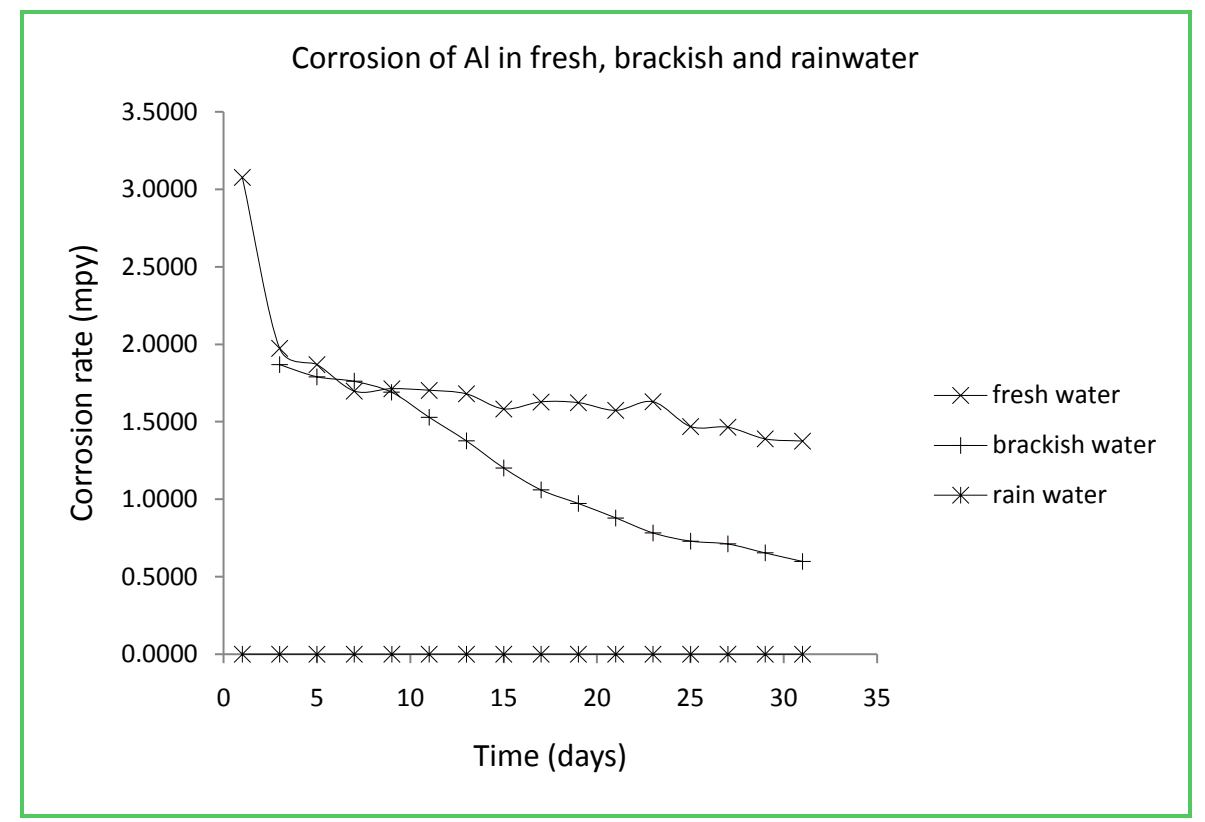

Figure 1. Corrosion rate of Aluminum in fresh, brackish and rainwater. 


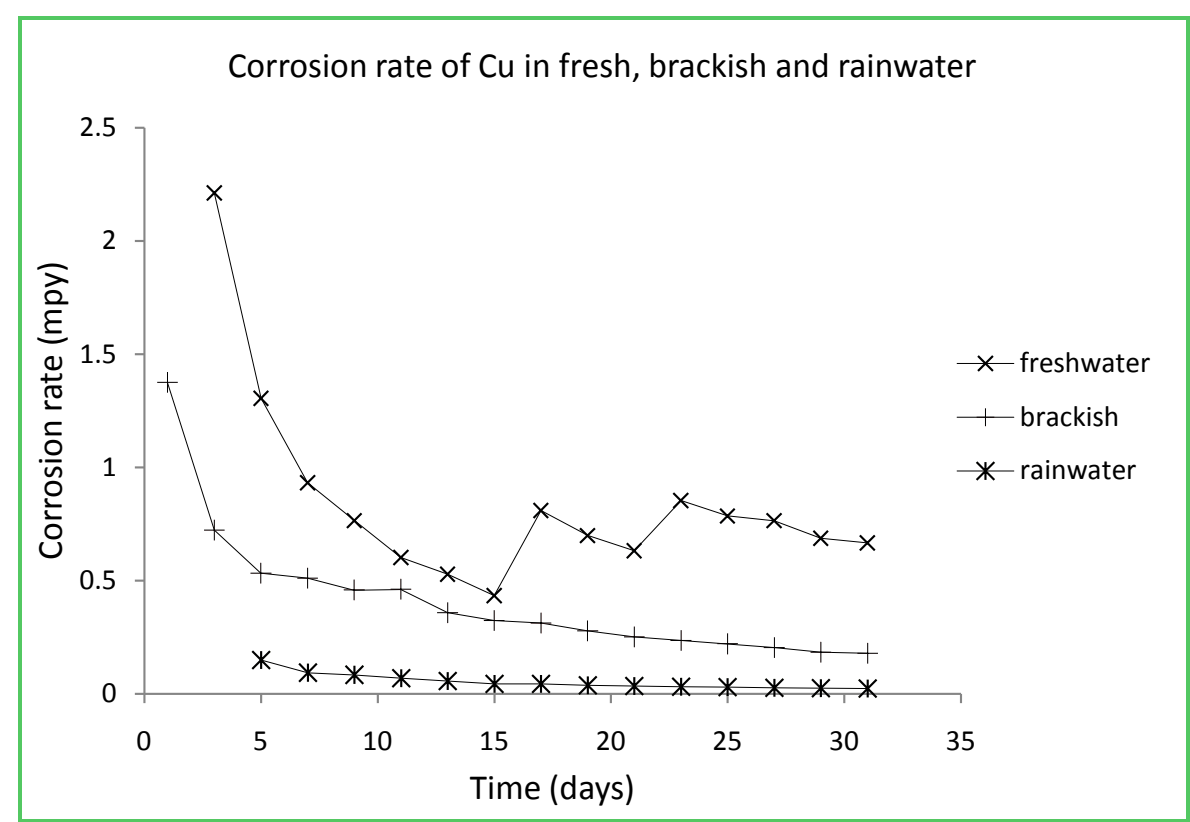

Figure 2. Corrosion rate of Copper in fresh, brackish and rainwater.

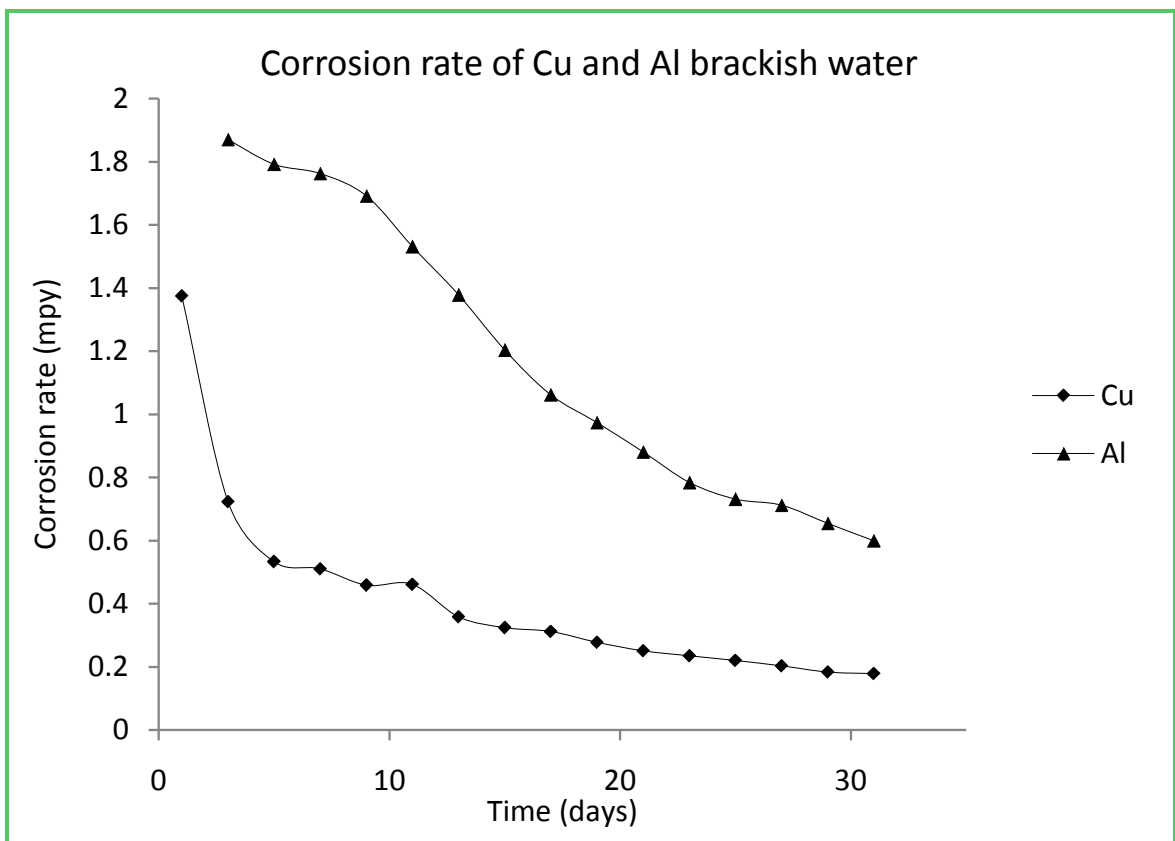

Figure 3. Comparison between rate of corrosion of copper and aluminum in brackish water.

the different environment. Furthermore, the study could be compared to similar studies done on the thermal and mechanical properties of nypa palm, which revealed that nypa palm could be used to make roofing sheets, mats, and boards which could withstand corrosion and cheaper to use as roofing materials than the metal sheets currently in use.

\subsection{Conclusions}

In this study, it is stated that for corrosion to take place, there must be the presence of an electrolyte, like water, salt water, soil or charged liquid medium. Therefore, from the above statement, it could be deduced that corro- 


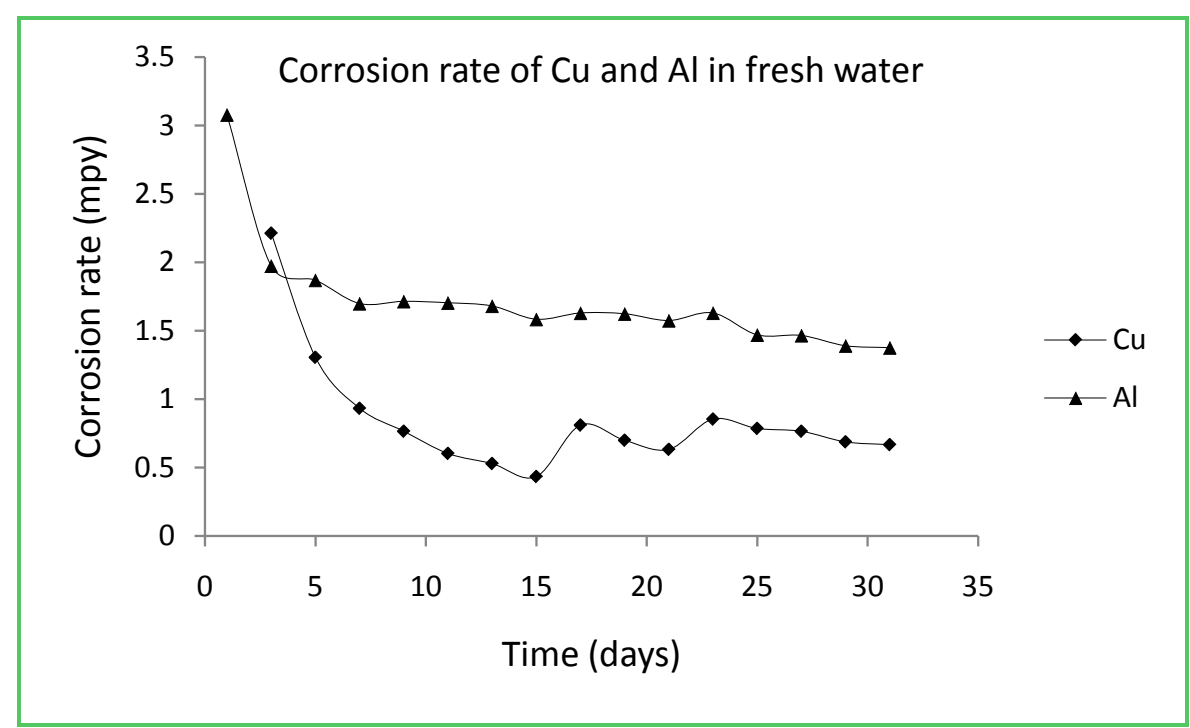

Figure 4. Comparison between rate of corrosion of copper and aluminum in freshwater.

sion could be enhanced by an electrolytic conduction mechanism. Thus, if an environment is more conductive, it exposes the material to high degree of electrolytic processes thereby leading to higher rate of corrosion. The different water samples used for experiment have high salinity or alkalinity and increase electrolytic process.

In conclusion, it is inferred that there are varying rates of corrosion of these materials depending on the particular environment as shown in the results of our study.

\subsection{Recommendation}

I recommend that further research be carried out on the health and socio-economic effects of these metals (Copper and Aluminium) on the populace, since they are widely used in our daily lives in homes and industries.

\section{References}

[1] Federal Republic of Nigeria (1992) Environmental Impact Assessment Decree No. 86.

[2] Aguiyi, N. (1992) Corrosion Control in the Oil and Gas Process Industry. Ochez Engineering Nigeria Limited, Lagos.

[3] King, E.M (1979) The Pipeline Contributions (ed. Wardley Smith.) Revention of Pollution. Graham and Trotman, New York.

[4] Ziu, C.G. 1995) Hand Book of Double Containment Piping Systems. McGraw-Hill, New York.

[5] Jeffery, C. and George, W. (1990) Sol-Gel Sciences. Academic Press, London.

[6] Peter, M.B. (1993) Environmental Impact Assessment Report on Mobil Oil Spillage; Mobil Facility 1993-1996. Nigeria.

[7] Fontana, M.G. (1986) Corrosion Engineering. 3rd Edition, McGraw-Hill, New York. 
Scientific Research Publishing (SCIRP) is one of the largest Open Access journal publishers. It is currently publishing more than 200 open access, online, peer-reviewed journals covering a wide range of academic disciplines. SCIRP serves the worldwide academic communities and contributes to the progress and application of science with its publication.

Other selected journals from SCIRP are listed as below. Submit your manuscript to us via either submit@scirp.org or Online Submission Portal.
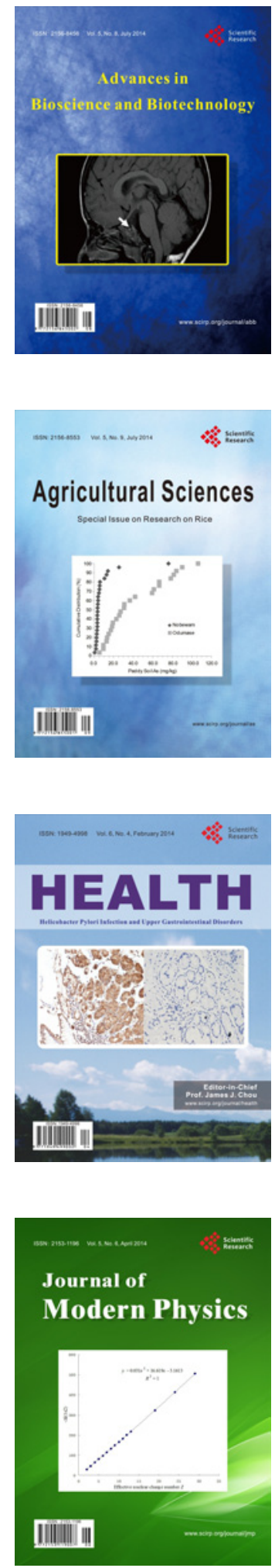
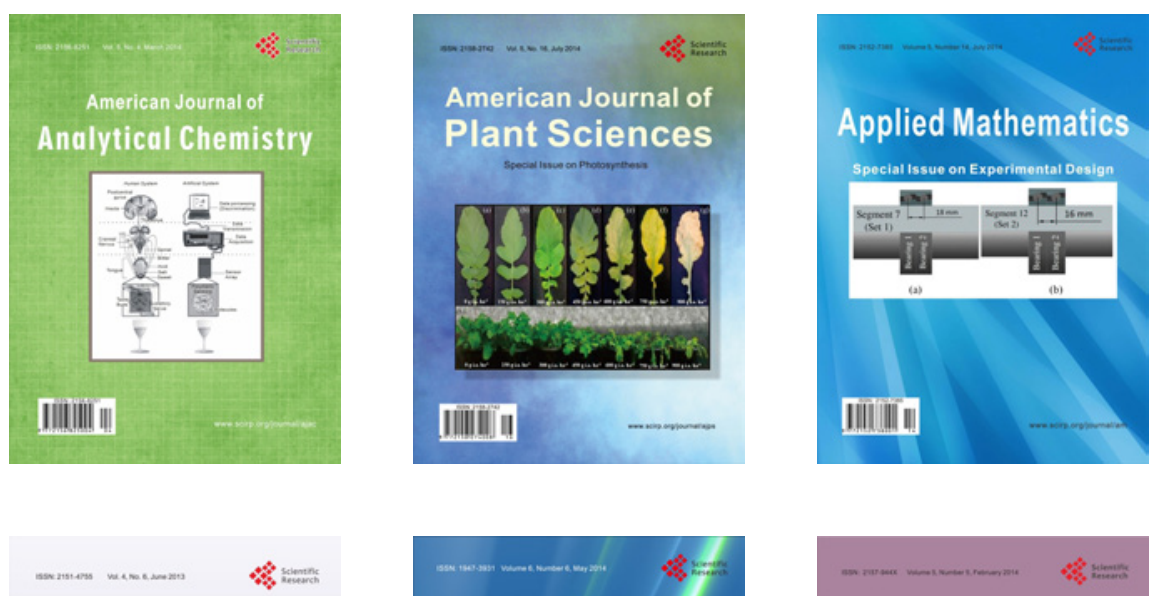

Creative Education
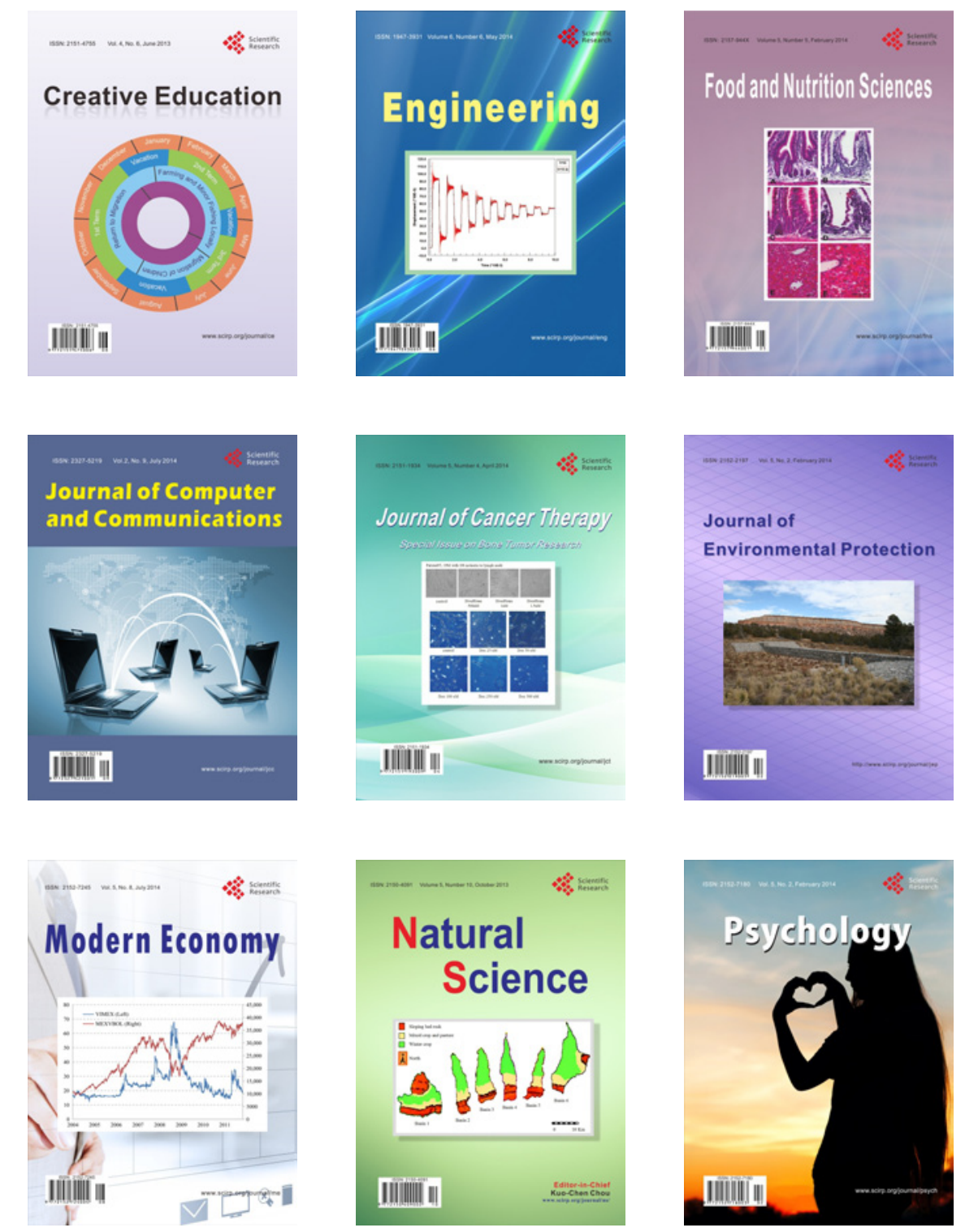